Check for updates

Cite this: RSC Adv., 2019, 9, 2412

Received 27th October 2018

Accepted 4th January 2019

DOI: $10.1039 / \mathrm{c} 8 \mathrm{ra0} 8910 \mathrm{~h}$

rsc.li/rsc-advances

\section{Study of diffuse phase transition and relaxor ferroelectric behavior of $\mathrm{Ba}_{0.97} \mathrm{Bi}_{0.02} \mathrm{Ti}_{0.9} \mathrm{Zr}_{0.05} \mathrm{Nb}_{0.04} \mathrm{O}_{3}$ ceramic}

\begin{abstract}
Z. Raddaoui, ${ }^{a}$ S. El Kossi, ${ }^{a}$ J. Dhahri, (D) ${ }^{* a}$ N. Abdelmoula ${ }^{b}$ and K. Taibi ${ }^{c}$
In the present work, structural and dielectrics properties of polycrystalline sample $\mathrm{Ba}_{0.97} \mathrm{Bi}_{0.02} \mathrm{Ti}_{0.9} \mathrm{Zr}_{0.05} \mathrm{Nb}_{0.04} \mathrm{O}_{3}$ (BBTZN) prepared by a molten-salt method were investigated. $\mathrm{X}$-ray diffraction analyses revealed the formation of a single-phase pseudocubic structure with a $P m \overline{3} m$ space group. Unlike the trend observed in classic ferroelectrics, the temperature dependence of the dielectric constants showed the presence of three sequences of structural phase transitions. In fact, the local disorder provides a frequency dependent relaxor like behaviours attributed to the dynamic of polar nanoregions (PNRs). The diffuse phase transition (DPT) analyzed using the modified Curie-Weiss law and Lorenz formula confirms the presence of short-range association between the nanopolar domains. The obtained values of the degree of diffuseness are found to be in the range of 1.58-1.78 due to the existence of different states of polarization and, hence, different relaxation times in different regions. The frequency dependence of temperature at dielectric maxima, which is governed by the production of PNRs at a high temperature, satisfies the Vogel-Fulcher (V-F) law. The temperature dependence of the electric modulus for various frequencies indicating a thermally activated relaxation ascribed to the Maxwell-Wagner $(M-W)$ space charge relaxation phenomenon.
\end{abstract}

\section{Introduction}

New industrial applications require advanced materials with interesting properties. Perovskite materials fall into this category of materials fall into this category of materials owing to their promising physical properties and potential manipulation in many industrial and engineering fields such as multilayer ceramic capacitors MLCCs, positive-temperature-coefficient resistors PTCRs, and piezoelectric transducers. ${ }^{\mathbf{1}-3}$ However, these days much research is directed towards lead free relaxor materials with a perovskite structure characterized by a translational symmetry breaking to form polar nanoregions (PNRs), which explains the origin of relaxor behavior. ${ }^{4}$ In this respect, compositional inhomogeneity plays a central role, and discrete ferroelectric nano-regions have been proposed to explain the diffused dielectric response. ${ }^{5}$ The first evidence of these inhomogeneities was provided by Burns and Dacol $^{6}$ who observed a deviation from the linear temperature dependence of the

${ }^{a}$ Laboratoire de la Matière Condensée et des Nanosciences, Université de Monastir, Faculté des Sciences de Monastir, Avenue de l'environnement, 5019 Monastir, Tunisia. E-mail: j.dhahri3000@gmail.com

${ }^{b}$ Laboratoire des Matériaux Ferroélectriques, LR-Physique-Mathématiques et Applications, Université de Sfax, Faculté des Sciences, Route de Soukra km 3.5 B.P 1171, 3000 Sfax, Tunisia

'Laboratoire de Sciences et Génie des Matériaux, Faculté de Génie Mécanique et Génie des Procédés, Université des Sciences et de la Technologie Houari Boumediene BP32, Bab Ezzouar 16111, Alger, Algeria optical index of refraction below a certain temperature during the cooling of the La-doped $\operatorname{PbZr}_{(1-x)} \mathrm{Ti}_{\mathrm{x}} \mathrm{O}_{3}$ samples.

Despite, the discovery of many attractive properties in some perovskite structures including relaxor behavior in $\mathrm{Pb}\left(\mathrm{Mg}_{1 /}\right.$ $\left.{ }_{3} \mathrm{Nb}_{2 / 3}\right) \mathrm{O}_{3}-\mathrm{PbTiO}_{3},{ }^{7,8} \mathrm{~Pb}\left(\mathrm{Mg}_{1 / 3} \mathrm{Nb}_{2 / 3}\right) \mathrm{O}_{3} \mathrm{~Pb}\left(\mathrm{Zr}_{0.52} \mathrm{Ti}_{0.48}\right) \mathrm{O}_{3},{ }^{9}$ and $\mathrm{Pb}\left(\mathrm{Zn}_{1 / 3} \mathrm{Nb}_{2 / 3}\right) \mathrm{O}_{3}-\mathrm{PbTiO}_{3}{ }^{10}$ they have net been put to application due to their volatility and toxicity. So many researchers have attempted to overcome this problem by doping $\mathrm{BaTiO}_{3}$ in the A or/and B sites to become a relaxor. ${ }^{\mathbf{1 1}}$ In fact, the discovery of the high-permittivity of the ferroelectric ceramic BT in 1943 (ref. 12) mode it subject of investigation in order to understand and manipulate its properties. These compounds present several polymorphic phase transitions used to correlate important dielectric/ferroelectric properties, such as variations in polymorphic phase transition temperatures, permittivity, and dielectric loss with chemical doping and ceramic microstructure. ${ }^{13-15}$

Incorporating $\mathrm{Bi}^{3+}$ in to this structure at $\mathrm{Ba}$ site was reported in many works and assumed that the relaxor behavior is induced by heterovalent substitution can be explained by the random-field-induced domain state. ${ }^{\mathbf{1 6 - 1 9}}$

Moreover, other researchers studied the effect of doping at $\mathrm{Ti}^{4+}$ site using more stable chemical ions and larger ionic size as $\mathrm{Zr}^{4+}$. They report a decrease of the electronic hopping conduction, and the existence of introduce a relaxor behavior in the BT attributed to the distribution of micro-polar regions along the structure. ${ }^{20}$ Introducing disorder on BT using $\mathrm{Nb}^{5+}$ lead to small 
inhomogeneities distribution and the creation of titanium vacancies. ${ }^{21}$ It is evident that more efforts are needed in this area in order to produce an ideal, low loss, highdielectric constant material that could be used for advanced capacitive applications. $^{22}$

Therefore, in this work we have synthesized the $\mathrm{Ba}_{0.97^{-}}$ $\mathrm{Bi}_{0.02} \mathrm{Ti}_{0.9} \mathrm{Zr}_{0.05} \mathrm{Nb}_{0.04} \mathrm{O}_{3}$ (BBTZN) ceramic by the molten-salt method. We have studied the effect of structure and microstructure on the dielectric properties of the polycrystalline BBTZN.

\section{Experimental details}

\subsection{Preparation of $\mathrm{Ba}_{0.97} \mathrm{Bi}_{0.02} \mathrm{Ti}_{0.9} \mathrm{Zr}_{0.05} \mathrm{Nb}_{0.04} \mathrm{O}_{3}$ perovskite sample}

A polycrystalline BBTZN sample was produced by the molten salt method using stoichiometric amounts of $\mathrm{BaCO}_{3}, \mathrm{Bi}_{2} \mathrm{O}_{3}$, $\mathrm{TiO}_{2}, \mathrm{ZrO}_{2}$ and $\mathrm{Nb}_{2} \mathrm{O}_{5}$ (having a purity of more than $99.9 \%$ for each of them). The precursors were weighed, then, thoroughly mixed in an agate mortar for $2 \mathrm{~h}$. The salt-precursor mixture was placed in an alumina crucible and heated at $800{ }^{\circ} \mathrm{C}$ for $24 \mathrm{~h}$. After cooling to room temperature, the mixture was washed with distilled water and filtered to remove the salts. After being dried at $100{ }^{\circ} \mathrm{C}$ in air and ground thoroughly, the compounds were pressed into disks (with a diameter of $8 \mathrm{~mm}$ and a thickness about $2 \mathrm{~mm}$ ), and sintered in air at $900{ }^{\circ} \mathrm{C}$ for $24 \mathrm{~h}$.

\subsection{Characterization of the sample}

The composition and microstructure of the BBTZN ceramic were analysed using scanning electron microscopy (SEM) equipped with an energy dispersive X-ray system (EDX). The pictures were taken at room temperature on a Phillips XL30 microscopy.

The crystal structure, as well as its purity were checked by $\mathrm{X}$ ray diffraction (XRD) using "PANalytical X'Pert Pro" diffractometer with $\mathrm{CuK}_{\alpha}$ radiation. Data a were collected at room temperature in the range of $2 \theta$ from 10 to $70^{\circ}$ with a step size of $0.017^{\circ}$ and a counting time of $18 \mathrm{~s}$ per step. The structural analysis was carried out by the standard Rietveld method. ${ }^{23}$

The dielectric properties were measured on discs under helium atmosphere as a function of both temperature (290-800 $\mathrm{K}$ ) and frequency ( $1 \mathrm{kHz}$ to $1 \mathrm{MHz}$ ) using a Wayne-Kerr 6425 component analyzer. All the dielectric data were collected while heating at a rate of $2 \mathrm{~K} \mathrm{~min}^{-1}$.

\section{Results and discussion}

The EDX chemical analysis of $\mathrm{Ba}_{0.97} \mathrm{Bi}_{0.02} \mathrm{Ti}_{0.9} \mathrm{Zr}_{0.05} \mathrm{Nb}_{0.04} \mathrm{O}_{3}$ sample is shown in Fig. 1(a). The EDX spectrum reveals the presence of $\mathrm{Ba}, \mathrm{Bi}, \mathrm{Ti}, \mathrm{Zr}, \mathrm{Nb}$ and $\mathrm{O}$ elements, which confirms that there is no loss of any integrated element during sintering, within the experimental errors. EDX analysis also showed that the chemical composition of the sample is close to the nominal one within the experimental uncertainties.

The surface of the BBTZN sample is shown in Fig. 1(b). It can be seen from the micrograph that the inhomogeneous microstructures of the grains and may be advantageous to explain the dielectric properties. ${ }^{24}$

The size distribution of particles presented in the inset of Fig. 1(b) was analysed quantitatively by fitting the histogram using a Lorentzian function. The mean diameter of BBTZN is of $2.5 \mu \mathrm{m}$ order.

The X-ray diffraction patterns for the polycrystalline BBTZN sample taken at room temperature are presented in Fig. 2. This figure, shows that the sample is in a single-phase condition with minor secondary phases identified as $\mathrm{Bi}_{2} \mathrm{O}_{3}$ phase arising from a small contamination during the sample preparation, which is in agreement with the results found by A. Aoujgal et al. ${ }^{25}$ The concentration of this impurity is obviously very small (a few percent). The structural parameters, unit cell volume and fitting parameters of the sample were refined by the standard refinement analysis. This refinement was performed with $P m \overline{3} m$ space group in the pseudocubic unit cell. The related results are listed in Table 1.

XRD profile analysis is a simple and powerful method to determine the average crystallite size $\mathrm{D}_{\mathrm{XRD}}$. Debye-Scherrer's formula showed the broadening of the XRD pattern attributed to the crystallite size-induced broadening: ${ }^{26}$

$$
D_{\mathrm{XRD}}=\frac{0.9 \lambda}{\beta \cos \theta}
$$

where $\lambda$ is the used $\mathrm{X}$-ray wavelength, $\theta$ and $\beta$ are, respectively, the diffraction angle and the full width at half-maximum of the most intense peak. The value of the average crystallite size $\left(D_{\mathrm{XRD}}\right)$ is listed in Table 1.

The crystallite size calculated by XRD data $\left(D_{\mathrm{XRD}}\right)$ was smaller than that obtained by SEM image, which indicates that each particle observed by SEM is formed by several crystallized grains. $^{27}$

According to the Halder-Wagner $(\mathrm{H}-\mathrm{W})$ method, the crystallite size $\left(D_{\mathrm{H}-\mathrm{W}}\right)$ and the strain $(\varepsilon)$ of the powder can be determined using the $\beta_{h k l}$ and planar spacing $d_{h k l}$ (the distance between adjacent planes in the set $(h k l)):^{28}$

$$
\left(\frac{\beta_{h k l}^{*}}{d_{h k l}^{*}}\right)^{2}=\left(\frac{1}{D_{\mathrm{H}-\mathrm{W}}}\right)\left(\frac{\beta_{h k l}^{*}}{d_{h k l}^{* 2}}\right)+\left(\frac{\varepsilon}{2}\right)^{2}
$$

where $\beta_{h k l}^{*}=\beta_{h k l} \cos \theta / \lambda$ and $d_{h k l}^{*}=2 \sin \theta / \lambda$. The results of crystallite size and micro-strain are summarized in Table 1 . The plot of eqn (2) is a straight line with a positive slope and a nonzero $y$-intercept (the inset of Fig. 2). The crystallite size $D_{\mathrm{H}-}$ ${ }_{\mathrm{w}}$ was determined from the slope inverse of the linearly fitted data and the root of the $y$-intercept gave the microstrain. The value of the crystallite size $\left(D_{\mathrm{H}-\mathrm{W}}\right)$ obtained from the $\mathrm{H}-\mathrm{W}$ analysis was compared to that obtained by Scherrer's method ( $\left.D_{\mathrm{XRD}}\right)$.

The temperature and frequency variations of the dielectric constant of BBTZN ceramics are shown in Fig. 3(a). To highlight the phase transitions, we plotted the curve of the differential dielectric constant $\left(\partial \varepsilon_{r}^{\prime} / \partial T\right) v s$. temperature in the insets of Fig. 3(b). Three peaks were observed on the dielectric curves. They originated from phase transitions from a cubic paraelectric to a tetragonal ferroelectric at the Curie temperature 

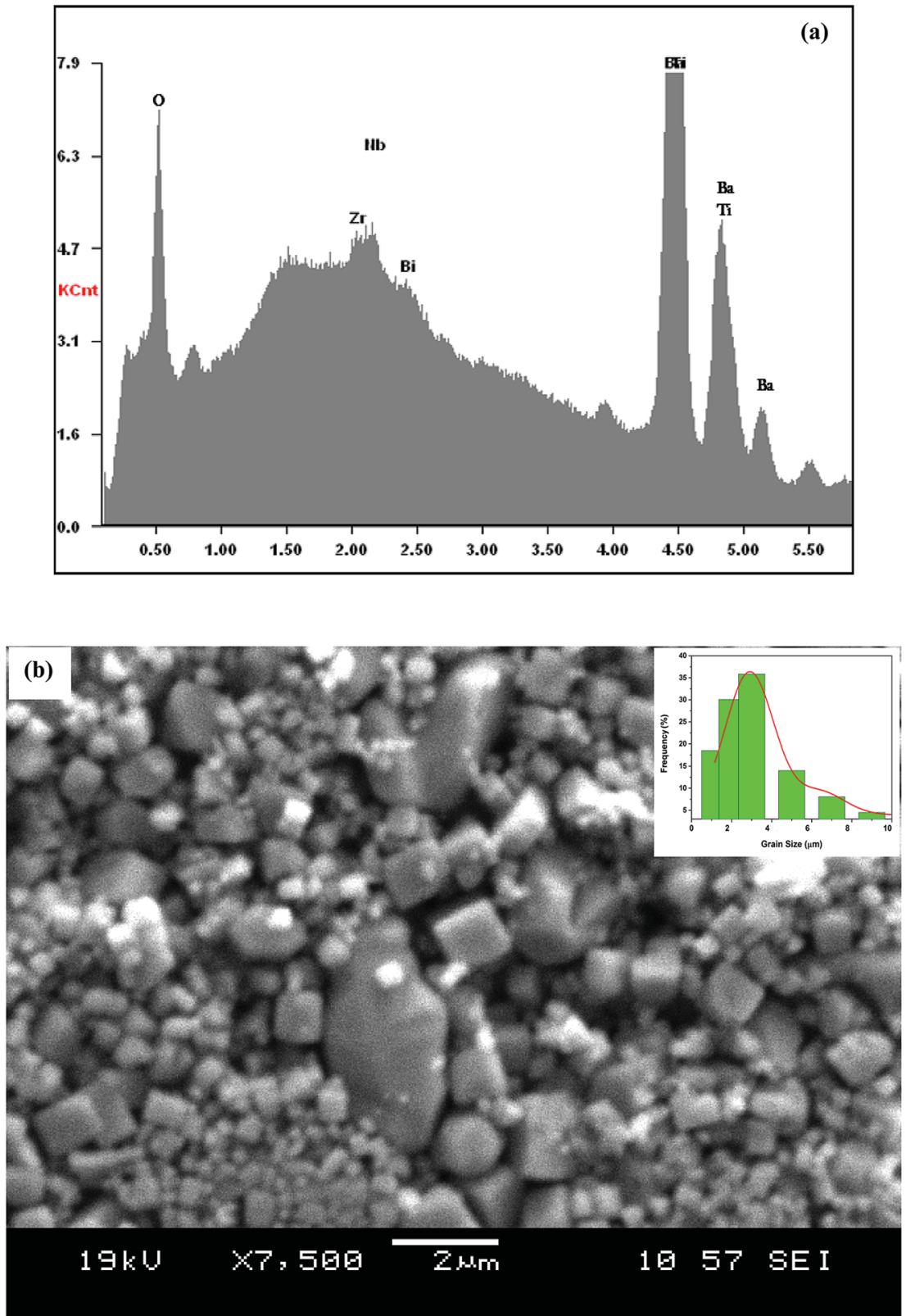

Fig. 1 (a) EDX analysis spectrum of $\mathrm{Ba}_{0.97} \mathrm{Bi}_{0.02} \mathrm{Ti}_{0.9} \mathrm{Zr}_{0.05} \mathrm{Nb}_{0.04} \mathrm{O}_{3}$ ceramic; (b) SEM image of the sample. The inset shows the size distribution histogram.

$\left(T_{\mathrm{C}}\right)$, then to an orthorhombic ferroelectric (at $T_{\mathrm{T}-\mathrm{O}}$ ), and finally to a rhombohedral ferroelectric (at $T_{\mathrm{O}-\mathrm{R}}$ ). These transitions are identical than those obtained on pure BT ceramics. ${ }^{29}$ Some researchers have reported low values of dielectric constant at $T_{\mathrm{c}}$ such that Li et al. ${ }^{30}$ report the maximum dielectric constant $\varepsilon_{r_{\max }}^{\prime}=200$, Hayashi et al. ${ }^{31}$ is of the order $\varepsilon_{r_{\max }}^{\prime}=650$.

Three regions of dielectric relaxations were observed in the present perovskite at the temperature ranges of 350-500 K, 500$620 \mathrm{~K}$ and $620-720 \mathrm{~K}$ with a maximum in the dielectric permittivity that shifted to a higher temperature with increasing frequency (Fig. 3(a)). This shift of each maximum in the dielectric permittivity for the three regions indicating diffused type phase transition. All the observed dielectric behaviours confirm the diffuse relaxor character for our composition. This indicates an important property of a disordered perovskite structure. In addition, we notice coexistence of low dielectric constant and high dielectric constant regions in dielectric materials. It was explained by the charge accumulation at the interface between the grain and grain boundaries (as shown in SEM images (Fig. 1(b))) and lead to a Maxwell-Wagner (MW) interfacial polarization. ${ }^{32}$

Compared to literature 33-35 (Table 2), we note that a low dielectric constant of the BBTZN sample, attribute able to the presence of $\mathrm{Bi}, \mathrm{Zr}, \mathrm{Nb}$ in the $\mathrm{BaTiO}_{3}$ lattice, which can minimize the local constraints and facilitate the motions of the domain. This great mobility of the domain walls in this ceramic, led to a low dielectric constant. 


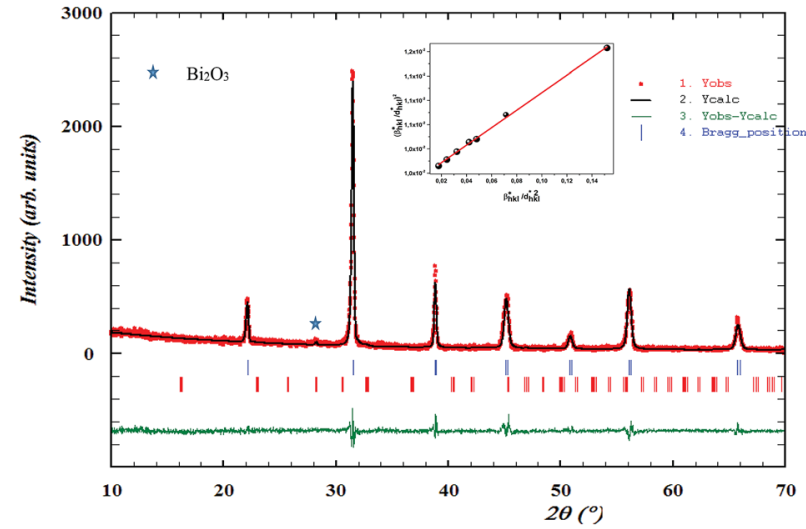

Fig. 2 Room temperature XRD pattern and Rietveld refinement result for $\mathrm{Ba}_{0.97} \mathrm{Bi}_{0.02} \mathrm{Ti}_{0.9} \mathrm{Zr}_{0.05} \mathrm{Nb}_{0.04} \mathrm{O}_{3}$ ceramic. The inset shows their crystal structure and fitted curves of the $\mathrm{H}-\mathrm{W}$ analysis.

Table 1 Refined structure parameters for $\mathrm{Ba}_{0.97} \mathrm{Bi}_{0.02} \mathrm{Ti}_{0.9} \mathrm{Zr}_{0.05^{-}}$ $\mathrm{Nb}_{0.04} \mathrm{O}_{3}$ after the Rietveld refinement of X-ray diffraction data at room temperature

\begin{tabular}{lll}
\hline & $\mathrm{Ba}_{0.97} \mathrm{Bi}_{0.02} \mathrm{Ti}_{0.9} \mathrm{Zr}_{0.05} \mathrm{Nb}_{0.04} \mathrm{O}_{3}$ \\
\cline { 2 - 3 } & Structure pseudo-cubic & $P m \overline{3} m$ phase \\
\hline \multirow{2}{*}{ Cell parameters } & $a=b(\AA)$ & $4.0135(4)$ \\
Thermal agitation & $V\left(\AA^{3}\right)$ & $64.652(1)$ \\
& $(\mathrm{Ba} / \mathrm{Bi}) B_{\text {iso }}\left(\AA^{2}\right)$ & 1.488 \\
& $(\mathrm{Ti} / \mathrm{Zr} / \mathrm{Nb}) B_{\text {iso }}\left(\AA^{2}\right)$ & 1.731 \\
Bond lengths and Bond angles & $\left(\mathrm{O}_{1}\right) B_{\text {iso }}\left(\AA^{2}\right)$ & 2.002 \\
& $d_{\mathrm{Ti}-\mathrm{O}}(\AA)$ & $2.006(7)$ \\
Discrepancy factors & $\theta_{(\mathrm{Ti}-\mathrm{O}-\mathrm{Ti})}\left({ }^{\circ}\right)$ & 180.00 \\
& $R_{\mathrm{p}}(\%)$ & 9.57 \\
Experimental density & $R_{\mathrm{wp}}(\%)$ & 12.5 \\
Theoretical density & $\chi^{2}$ & 1.78 \\
Compactness & $\left.d_{\text {theo }}(\mathrm{g} \mathrm{cm})^{-3}\right)$ & 6.142 \\
Average crystallite size & $d_{\exp }\left(\mathrm{g} \mathrm{cm}{ }^{-3}\right)$ & 5.97 \\
& $C$ & 0.97 \\
& $\langle D\rangle_{\mathrm{XRD}}(\mathrm{nm})$ & 64.2 \\
& $\langle D\rangle_{\mathrm{H}-\mathrm{W}}(\mathrm{nm})$ & 91 \\
& $\varepsilon$ & 0.002 \\
& &
\end{tabular}

The broad peak or diffusiveness in $\varepsilon^{\prime}(T)$ occurred due to fluctuations in the composition and structural disorder in the cationic arrangement on one or more site of the crystal structure. The local disorder in the system led to the formation of polar nanoregions (PNRs) of different sizes and local curie points. The dynamics of these PNRs is responsible for the diffuse phase transition (DPT). ${ }^{36}$

The width of the transition represents the DPT, which is very important in ferroelectric materials.

We can define ' $D$ ' is the characterizing parameter of diffuseness degree. It is the temperature interval where the volume of polar microscopic regions changes due to the appearance of new microscopic polar regions. This is defined as: ${ }^{37}$

$$
D=T_{\left(\frac{\partial \varepsilon_{r}^{\prime}(T)}{\partial T} \min \right)}-T_{\left(\frac{\partial \varepsilon_{r}^{\prime}(T)}{\partial T} \max \right)}
$$

where $T_{\left(\frac{\partial \varepsilon_{r}^{\prime}(T)}{\partial T} \min \right)}$ and $T_{\left(\frac{\partial \varepsilon_{r}^{\prime}(T)}{\partial T} \max \right)}$ are the temperature when $\partial \varepsilon_{r}^{\prime} / \partial T$ reaches the minimum and maximum, respectively. The curves for the $\partial \varepsilon_{r}^{\prime} / \partial T$ against $(T)$ for the three regions I, II and III are shown in Fig. 3(c-e). The temperature interval between $T_{\left(\frac{\partial \varepsilon_{r}^{\prime}(T)}{\partial T} \min \right)}$ and $T_{\left(\frac{\partial \varepsilon_{r}^{\prime}(T)}{\partial T} \max \right)}$ reflects the diffuseness degree microscopically. The vertical dashed lines in Fig. 3(c-e) correspond to $T_{\left(\frac{\partial \varepsilon_{r}^{\prime}(T)}{\partial T} \min \right)}$ and $T_{\left(\frac{\partial \varepsilon_{r}^{\prime}(T)}{\partial T} \max \right)}$ values. $D$ is the interval between $T_{\left(\frac{\partial \varepsilon_{r}^{\prime}(T)}{\partial T} \min \right)}$ and $T_{\left(\frac{\partial \varepsilon_{r}^{\prime}(T)}{\partial T} \max \right)}$.

The values of diffuseness decreases with the increase in temperature. This indicates that the phase transition from paraelectric-ferroelectric is the transition that occurs with less diffuse $(D=6 \mathrm{~K})$ disorder, while the phase transition tetragonal to orthorhombic phase transition is the transition that occurs with more diffuse $(D=44 \mathrm{~K})$ disorder. The orthorhombic to rhombohedral phase transition is the transition more diffuse $(D$ $=55 \mathrm{~K}$ ) disorder.

To explain the ferroelectric behavior with DPT phenomenon of the dielectric materials, Curie and Weiss propose the CurieWeiss law. ${ }^{38}$ When the temperature is above $T_{\mathrm{c}}$, the dielectric normal behavior follows the $\mathrm{C}-\mathrm{W}$ law as follows:

$$
\varepsilon_{r}^{\prime}=\frac{C}{\left(T-T_{0}\right)} \quad\left(T>T_{\mathrm{c}}\right)
$$

where $C$ and $T_{0}$ are the $\mathrm{C}-\mathrm{W}$ constant and the $\mathrm{C}-\mathrm{W}$ temperature, respectively.

The inverse of dielectric constant $\left(1 / \varepsilon_{r}^{\prime}\right)$ as a function of temperature at $1 \mathrm{kHz}$ for BBTZN ceramic sample is plotted in Fig. 4. The two parameters $C$ and $T_{0}$ obtained by fitting the inverse dielectric to eqn (4) are summarized in Table 2.

The value of Curie constant obtained is in the order of $10^{5}$ that is normally observed for displacive ferroelectrics type. $\left(T_{\mathrm{C}}\right.$ $\neq T_{0}$ ) shows that the phase transition is of a first order type. ${ }^{39}$ All these dielectric results are in agreement with relaxor ferroelectric behavior for three regions.

In addition, we notice that the curves can be divided into three regions. The first region represents the ferroelectric behavior up to the transition at $T_{\mathrm{m}}$. The second region, near the transition, indicates a diffused transition up to a temperature $T_{\mathrm{C}-\mathrm{W}}$. The third region represents the linear behavior of $1 / \varepsilon^{\prime}$ as a function of temperature following the Curie-Weiss relation. It is clear from the above figures that for both samples at $T>T_{\mathrm{C}-\mathrm{W}}$, a normal Curie-Weiss behavior is found.

The parameter $\Delta T_{\mathrm{m}}$, which is often used to show the degree of deviation from the Curie-Weiss law, is defined as follows:

$$
\Delta T_{\mathrm{m}}=T_{\mathrm{C}-\mathrm{W}}-T_{\mathrm{m}}
$$



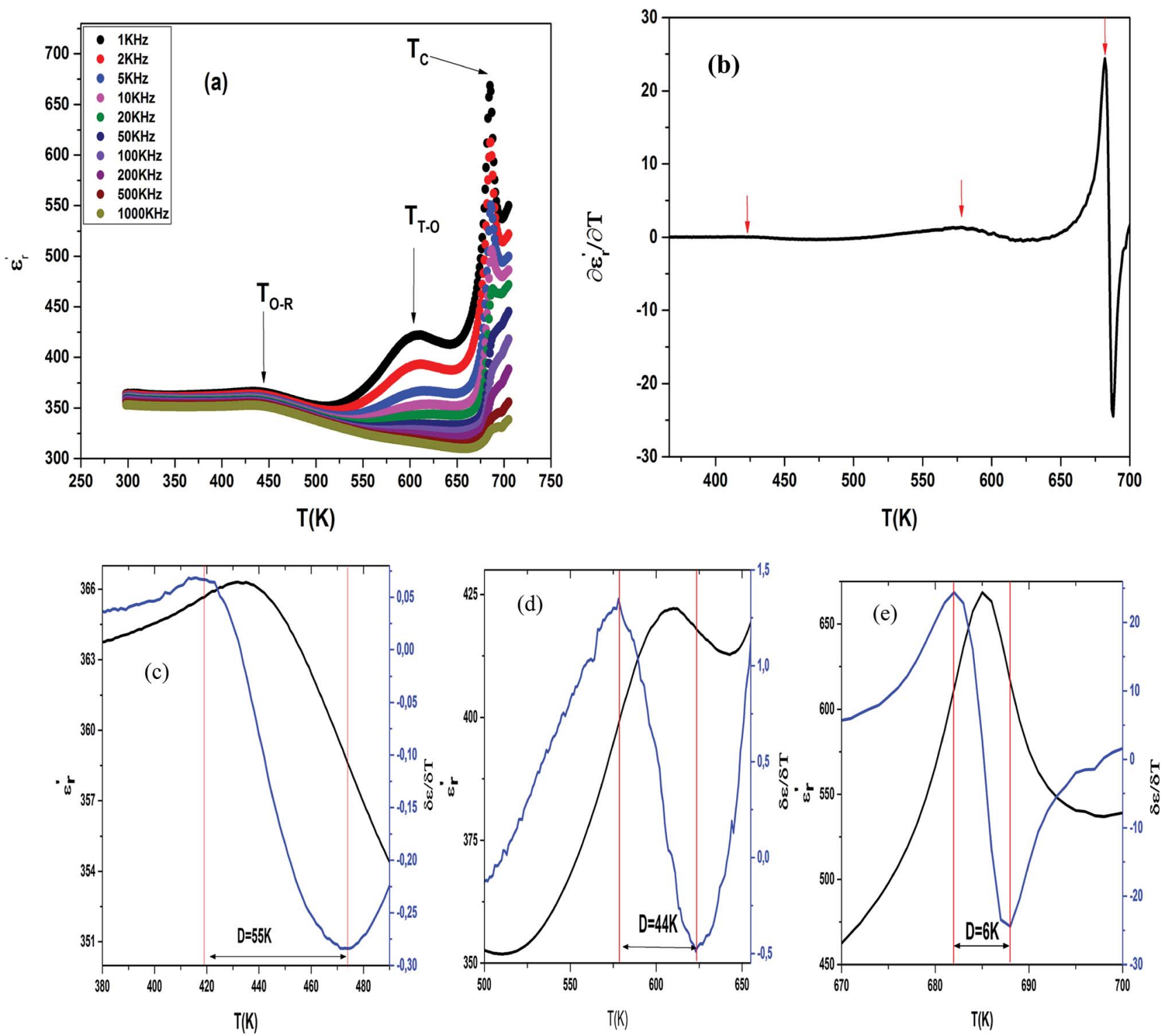

Fig. 3 Temperature dependence of dielectric properties of $\mathrm{Ba}_{0.97} \mathrm{Bi}_{0.02} \mathrm{Ti}_{0.9} \mathrm{Zr}_{0.05} \mathrm{Nb}_{0.04} \mathrm{O}_{3}$ at different frequencies (a), variation of $\partial \varepsilon_{r}^{\prime} / \partial T$ of $\mathrm{Ba}_{0.97} \mathrm{Bi}_{0.02} \mathrm{Ti}_{0.9} \mathrm{Zr}_{0.05} \mathrm{Nb}_{0.04} \mathrm{O}_{3}$ ceramic (b), the value of the diffuseness degree for this composition of region I (c), region II (d), region III (e).

Table 2 Parameters obtained from the temperature dependence of dielectric permittivity

\begin{tabular}{llll}
\hline Compounds & Ref. & $\varepsilon_{\mathrm{m}}(1 \mathrm{kHz})$ at $T_{\mathrm{c}}$ & $T_{\mathrm{c}}$ \\
\hline $\mathrm{Ba}_{0.97} \mathrm{Bi}_{0.02} \mathrm{Ti}_{0.9} \mathrm{Zr}_{0.05} \mathrm{Nb}_{0.04} \mathrm{O}$ & This work & 669 & 655 \\
$\mathrm{BaTiO}_{3}$ & 29 & 200 & 415 \\
$\mathrm{BaTiO}_{3}$ & 30 & 650 & -
\end{tabular}

where $T_{\mathrm{m}}$ denotes the temperature of the dielectric constant maximum $\left(\varepsilon_{r_{\max }}^{\prime}\right)$ and $T_{\mathrm{C}-\mathrm{W}}$ represents the temperature from which the dielectric constant starts to deviate from the CurieWeiss law. The various constants are listed in Table 2. The deviation from the Curie-Weiss behavior was qualified to a short-range association between the nanopolar domains. In addition, the deviation from Curie-Weiss law within a certain temperature interval above $T_{\mathrm{m}}$ is one of the salient features of relaxor ferroelectrics.

The relaxor behavior in ferroelectric compound is usually affected by the compositional fluctuation, the merging of micropolar regions into macropolar regions, or a coupling of order parameter and local disorder mode through the local strain. $^{40}$

Because the radius of $\mathrm{Bi}^{3+}(0.117 \mathrm{~nm})$ is smaller than that of $\mathrm{Ba}^{2+}(0.161 \mathrm{~nm})$ and $\mathrm{Zr}^{4+}(0.072 \mathrm{~nm})$, and the radius of $\mathrm{Ti}^{4+}$ $(0.061 \mathrm{~nm})$ is close to that of $\mathrm{Nb}^{5+}(0.064 \mathrm{~nm}),{ }^{41}$ the complex substitution at A-site and B-site tends to cause inhomogeneous composition distribution and disordered crystal structure.

Therefore, according to our results, the observed relaxation phenomena is attributed to the multi-ion coexistence at the A and B-sites. Different effects of A-site substitution on cation ordering and the stability of the polar region are considered to 

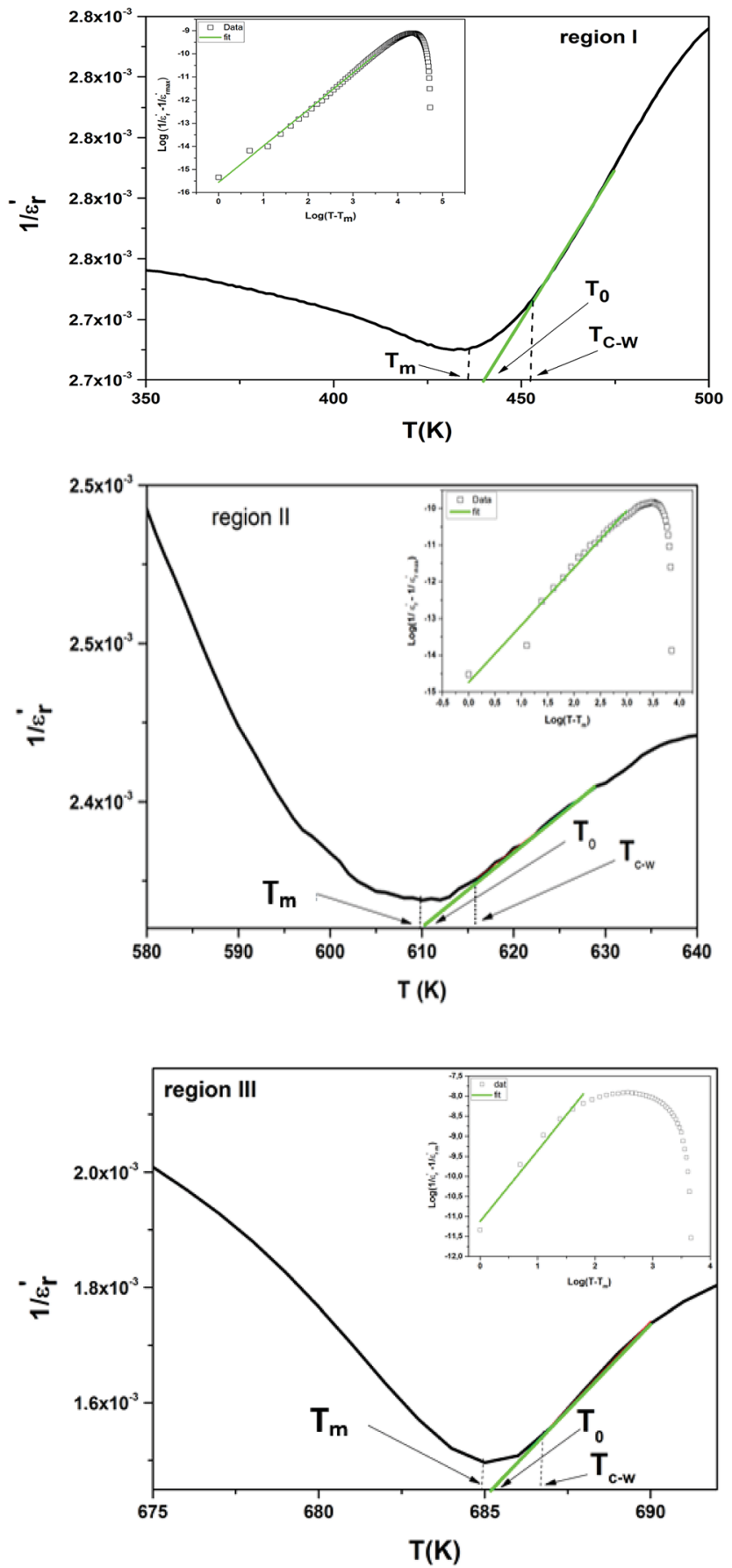

Fig. 4 Temperature dependence of inverse of permittivity $1 / \varepsilon^{\prime}$ at $1 \mathrm{kHz}$ for $\mathrm{Ba}_{0.97} \mathrm{Bi}_{0.02} \mathrm{Ti}_{0.9} \mathrm{Zr}_{0.05} \mathrm{Nb}_{0.04} \mathrm{O}_{3}$ ceramic: region I, region $\mathrm{II}$ and region III. The insets are plots of $\log \left(\frac{1}{\varepsilon_{r}^{\prime}}-\frac{1}{\varepsilon_{r_{\max }^{\prime}}^{\prime}}\right)$ as a function of $\log (T$ $-T_{m}$ ) at $1 \mathrm{kHz}$ for the compound: region I, region II and region III.

be based on the polarizability of cations and the tolerance factor of the perovskite structure. For perovskites with the $\mathrm{ABO}_{3}$ general formula, the following equation can be used to calculate the tolerance factor $(t)$ :

$$
t=\frac{r_{\left(\mathrm{Ba}^{2+}, \mathrm{Bi}^{3+}\right)}+r_{\mathrm{O}^{2-}}}{\sqrt{2}\left(r_{\left(\mathrm{Ti}^{4+}, \mathrm{Zr}^{4+}, \mathrm{Nb}^{5+}\right)}+r_{O^{2-}}\right)}
$$

The tolerance factor value was estimated $t=0.93$. It was found within the range of a stable perovskite structure.

So, $\mathrm{Ba}^{2+}$ cations can stabilize normal ferroelectrics due to the larger ionic diameter and higher polarizability. While $\mathrm{Bi}^{3+}$ cations in A-sites behave as a typical destabilizer against normal ferroelectrics and induce paraelectric behavior due to smaller ionic diameter and lower polarization. In this case more macrodomains (long-range ordered regions) in $\mathrm{Bi}$ substituted ceramic will breakup into micropolar regions than those in $\mathrm{BaTi}_{0.9} \mathrm{Zr}_{0.05} \mathrm{Nb}_{0.04} \mathrm{O}_{3}$ ceramic. Mechanical stress in the grain is one of the causes of relaxor behavior in the $\mathrm{Ti}^{4+}, \mathrm{Zr}^{4+}$ and $\mathrm{Nb}^{5+}$ mixed composition.

Similar behaviors are reported for $\mathrm{Ba}_{(1-x)} \mathrm{Bi}_{2 x / 3} \mathrm{Zr}_{0.15} \mathrm{Ti}_{0.85} \mathrm{O}_{3}$ and was attributed to the diffuse ferroelectric phase transition. ${ }^{42} \mathrm{~N}$. Haddadou et al. ${ }^{43}$ report for the $\mathrm{Ba}_{0.925} \mathrm{Bi}_{0.05}(-$ $\left.\mathrm{Ti}_{0.95-x} \mathrm{Zr}_{x}\right) \mathrm{Sn}_{0.05} \mathrm{O}_{3}(0.05 \leq x \leq 0.30)$ ceramics than the low $\mathrm{Zr}$ composition was found to exhibit a flat $\varepsilon_{r}^{\prime}(T)$ curve with stable dielectric permittivity in a large range of temperature, promising for the X7R specifications.

An empirical relaxation strength characterizes the frequency dispersion and could be defined by the parameter $\Delta T_{\text {relax }}=T_{\mathrm{m}}$ $(1 \mathrm{MHz})-T_{\mathrm{m}}(1 \mathrm{kHz}) .{ }^{44}$ The values of $\Delta T_{\text {relax }}$, as shown in Table 2 , the values of $\Delta T_{\text {relax }}$ are higher in the regions (I and III). The substitution of $\mathrm{Bi}^{3+}$ for $\mathrm{Ba}^{2+}$ in site $\mathrm{A}$ promote the relaxor behavior with a low amplitude of dielectric constant. ${ }^{45}$ Also substituting $\mathrm{Nb}^{5+}, \mathrm{Zr}^{4+}$ for $\mathrm{Ti}^{4+}$ to heightens the transition temperatures. According to the bibliography for rate of ion $\mathrm{Zr}^{4+}$ $=5 \%$ we found the diffuse phase transition ${ }^{\mathbf{4 6 , 4 7}}$ and the effect of the $\mathrm{Nb}^{5+}$ ions to improve the dielectric property. ${ }^{48}$

To further study the phase transition behavior of the BBTZN sample, we calculated the diffuseness parameter using the modified Curie-Weiss law: ${ }^{49}$

$$
\frac{1}{\varepsilon_{r}^{\prime}}-\frac{1}{\varepsilon_{r_{\max }}^{\prime}}=\frac{\left(T-T_{\mathrm{m}}\right)^{\gamma}}{C_{1}} \quad T>T_{\mathrm{m}}
$$

The diffuseness coefficient $\gamma$ allows understanding the character of the phase transition; $C_{1}$ is a constant quantity and $\varepsilon_{r_{\max }}^{\prime}$ is the peak dielectric permittivity at temperature $T_{\mathrm{m}}$. In general, the value of $\gamma$ between these limits $(1<\gamma<2)$ provide an incomplete diffuse phase transition. For normal ferroelectrics $\gamma$ approximate to 1 but relaxor ones approximate to 2 .

The inset of Fig. 4 shows the plots of $\ln \left(1 / \varepsilon_{r}^{\prime}-1 / \varepsilon_{r_{\max }}^{\prime}\right)$ versus $\ln \left(T-T_{\mathrm{m}}\right)$ at $1 \mathrm{kHz}$ for BBTZN ceramic sample. The obtained values of ' $\gamma$ ' are found to be in the range of 1.58-1.78 (Table 2), which corresponds to the diffuse phase transition due to the existence of different states of polarization and, hence, different relaxation times in different regions. ${ }^{50}$

The values of ' $\gamma$ ' indicate that the paraelectric-ferroelectric phase transition $(\gamma=1.78)$ is the transition that occurs with more disorder, while the phase transition from orthorhombic to rhombohedral $(\gamma=1.58)$ is the transition that occurs with less disorder.

The incorporation of $\mathrm{Bi}_{2} \mathrm{O}_{3}$ induced the ferroelectric relaxor behavior in the $\mathrm{Ba}_{0.8} \mathrm{Sr}_{0.2} \mathrm{TiO}_{3}$ perovskite. The relaxor character based on empirical parameters such as $\gamma$ and the originated is 
form the micro-polar clusters, which stemmed from the heterovalent substitutions of $\mathrm{Bi}^{3+}$ at A site. ${ }^{42}$

In addition, the relaxor behavior with DPT occurs at the $\mathrm{B}$ site of the $\mathrm{ABO}_{3}$ perovskite structure, where $\mathrm{Nb}^{5+}$ and $\mathrm{Ti}^{4+}$ also possess different valences and ionic radii, as reported by Z. Sun et al. ${ }^{51}$ for the perovskite $\mathrm{Ba}\left(\mathrm{Zr}_{0.2} \mathrm{Ti}_{0.8}\right)_{(1-x)} \mathrm{Nb}_{x} \mathrm{O}_{3}$ ceramics. This difference for ionic radii produce the formation of the local electric fields owing to the local charge imbalance and the local elastic fields due to local structure distortions, prevents the long-range dipole alignment, i.e., giving rise to the PNRs.

Therefore, the origin of the observed relaxor character in BBTZN is the substitution of $\mathrm{Bi}^{3+}$ for $\mathrm{Ba}^{2+}$ in A site and $\left(\mathrm{Zr}^{4+}\right.$, $\mathrm{Nb}^{5+}$ ) for $\mathrm{Ti}^{4+}$ in $\mathrm{B}$ site. This inhomogeneous distribution leads to the compositional fluctuation which may result in microscopic heterogeneity with different Curie points and cause the observed diffuseness. ${ }^{52}$ Furthermore, it creates the different states of polarization and hence different relaxation time in different regions and also to the formation of a local charge imbalance and defects, which cause, in turn, the thermal activation conduction of mobile ions/or the other defects contributing to the observed dielectric dispersion. ${ }^{53}$ However, many studies have shown that $\gamma$ is not a good parameter to give the exact degree of dielectric relaxation in perovskites. ${ }^{54}$ Recently, both empirical relations, Gaussian-distribution above $T_{\mathrm{m}}$ and the better Lorentz type above and below $T_{\mathrm{m}}$, have been attempted to express fairly the relaxor feature. Smolenskii and co-works ${ }^{55}$ introduced the concept of Gaussian distribution of the $T_{\mathrm{m}}$ to the small micro-regions considered noncorrelated. According to such an assumption, the permittivity $\varepsilon_{r}$ as a function of temperature is expressed as: ${ }^{56}$

$$
\frac{1}{\varepsilon_{r}^{\prime}}=\frac{1}{\varepsilon_{r_{\max }}^{\prime}}+\frac{\left(T-T_{\mathrm{m}}\right)^{2}}{2 \delta^{2}}
$$

where $\varepsilon_{r}^{\prime}$ is the dielectric constant, $\varepsilon_{r_{\max }}^{\prime}$ is its maximum value, $T_{\mathrm{m}}$ is the temperature corresponding to this maximum, and $\delta$ is the Gaussian coefficient of diffuseness.

Fig. 5 shows the fitted results from eqn (8). The best Gaussian fitting parameter $(\delta)$ is shown in Table 3.

It has been emphasized in the literature that a description of the high temperature slope of the dielectric peak in ferroelectrics with or without DPT, and classical relaxor materials can be well described above and below $T_{\mathrm{m}}$ with the Lorenz formula empirical relation: ${ }^{57}$

$$
\frac{\varepsilon_{\mathrm{A}}}{\varepsilon_{r}^{\prime}}=1+\frac{\left(T-T_{\mathrm{A}}\right)^{2}}{2 \delta_{\mathrm{A}}{ }^{2}}
$$

where $\delta_{\mathrm{A}}$ reflects the diffuseness of the dielectric relaxation, $T_{\mathrm{A}}$ $\left(T_{\mathrm{A}} \neq T_{\mathrm{m}}\right)$ and $\varepsilon_{\mathrm{A}}$ are the fitting parameters defining the temperature of the peak position and magnitude of the Lorentz peak. The temperature dependent dielectric data $\varepsilon_{r}^{\prime}$ measured on BBTZN ceramic could be fitted by the Lorentz-type quadratic relation in the two different temperature ranges $T<T_{\mathrm{m}}$ and $T>$ $T_{\mathrm{m}}$, respectively. The values of $\delta_{\mathrm{A}}, T_{\mathrm{A}}$ and $\varepsilon_{\mathrm{A}}$ obtained from the experimental data, fitted by eqn (9) are listed in Table 3, and the fitting curves are shown in Fig. 6.
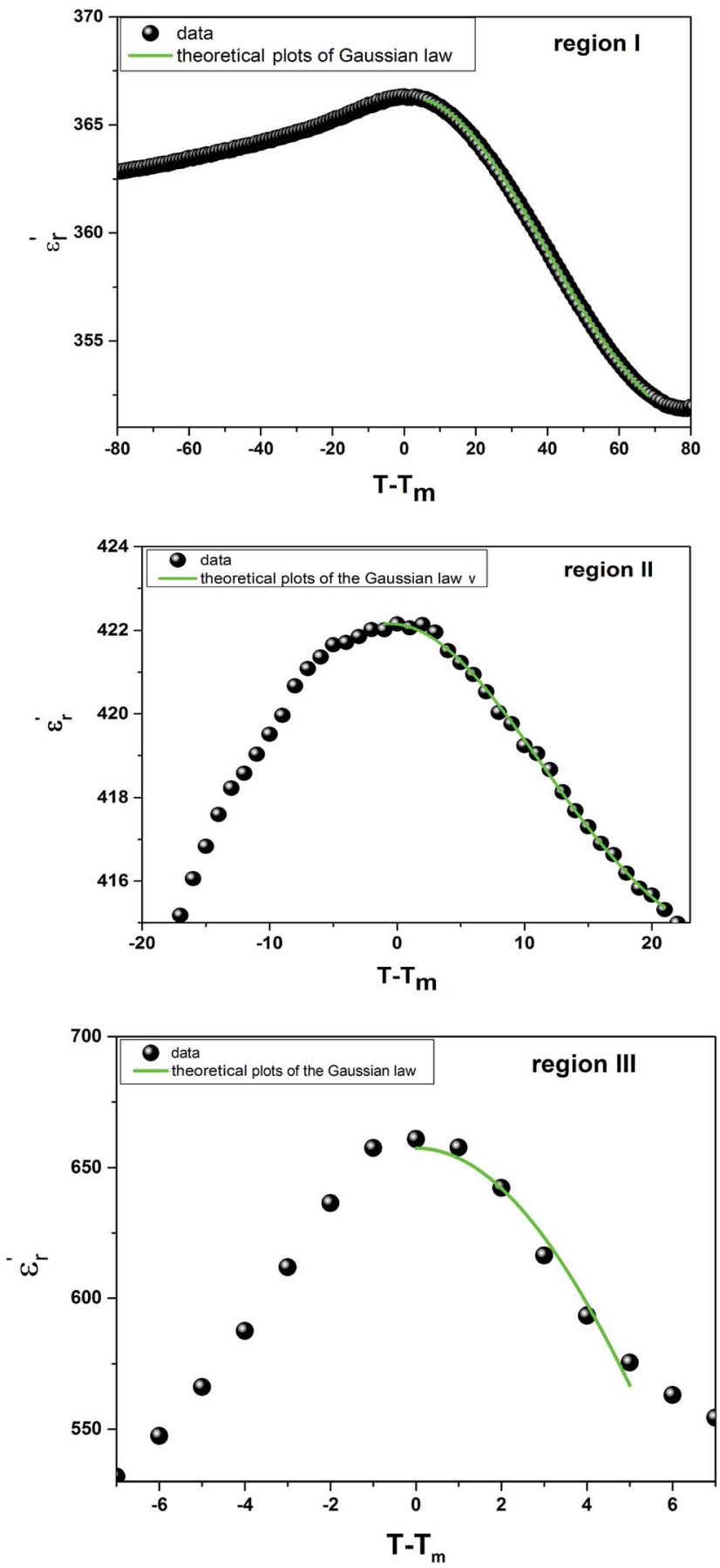

Fig. 5 The experimental and fitted dielectric data as a function of temperature for $\mathrm{Ba}_{0.97} \mathrm{Bi}_{0.02} \mathrm{Ti}_{0.9} \mathrm{Zr}_{0.05} \mathrm{Nb}_{0.04} \mathrm{O}_{3}$ ceramic using the Gaussian distribution.

We notice the very different fitting parameters $\delta_{\mathrm{A}}$ in two different temperature ranges $\left(T<T_{\mathrm{m}}\right.$ and $\left.T>T_{\mathrm{m}}\right)$, which indicates that there should be two polarization processes in these compound for the three transitions. Furthermore, $\delta_{\mathrm{A}}$ increased in the two ranges of temperature, which suggests increasing the diffuseness. This behavior explains by the $\mathrm{Bi}^{3+}$ substitution in $\mathrm{A}$ site and $\left(\mathrm{Zr}^{4+}, \mathrm{Nb}^{5+}\right)$ for $\mathrm{Ti}^{4+}$ in $\mathrm{B}$ site is found to induce chemical and structural inhomogeneity that leads to structural disorder reflected as increasing diffuseness in the transition. 
Table 3 Gaussian distribution and Lorentz type fitting parameters of $\mathrm{Ba}_{0.97} \mathrm{Bi}_{0.02} \mathrm{Ti}_{0.9} \mathrm{Zr}_{0.05} \mathrm{Nb}_{0.04} \mathrm{O}_{3}$ ceramic

\begin{tabular}{|c|c|c|c|c|c|c|c|c|c|}
\hline & $\Delta T_{\text {relax }}(\mathrm{K})$ & $\Delta T_{\text {diffuse }}(\mathrm{K})$ & $\Delta T_{\mathrm{m}}(\mathrm{K})$ & $C\left(10^{5} \mathrm{~K}\right)$ & $\Delta \varepsilon_{r}^{\prime} / \varepsilon_{r}^{\prime}$ & $\gamma$ & $T_{\mathrm{m}}$ & $\begin{array}{l}\varepsilon_{\mathrm{m}} \\
(1 \mathrm{kHz})\end{array}$ & $T_{\text {transitions }}(\mathrm{K})$ \\
\hline Regions I & 2 & 68 & 17 & 5.1 & 0.04 & 1.58 & 435 & 366 & 435 \\
\hline Regions III & 21 & 73 & 3 & 0.14 & 0.51 & 1.78 & 655 & 669 & 655 \\
\hline
\end{tabular}

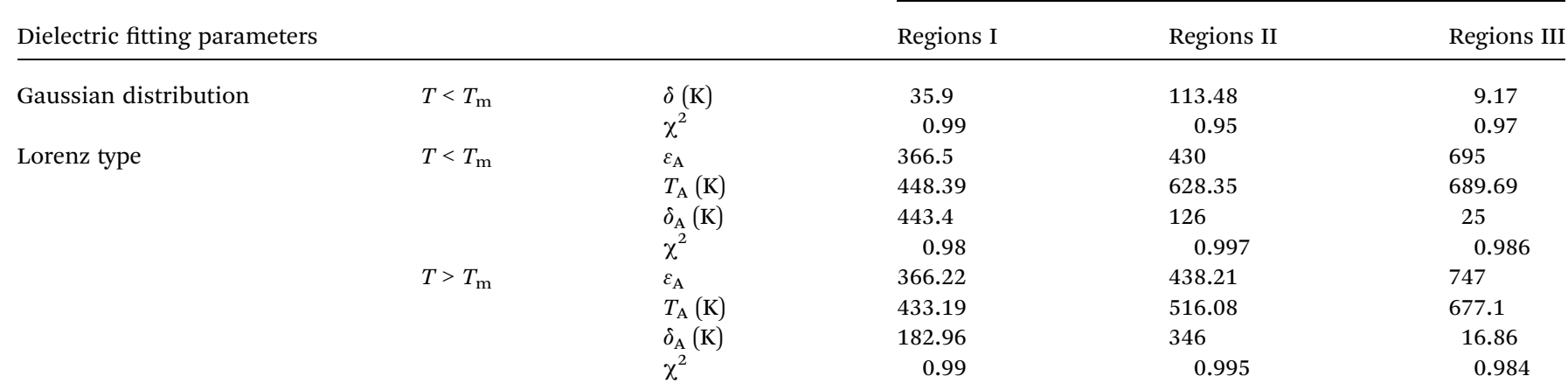

$\mathrm{Ba}_{0.97} \mathrm{Bi}_{0.02} \mathrm{Ti}_{0.9} \mathrm{Zr}_{0.05} \mathrm{Nb}_{0 .} 3$

Comparing the Lorenz type and Gaussian distribution for $T>$ $T_{\mathrm{m}}$, we note that the diffuseness of the dielectric relaxation are close. From the temperature dependence of $\varepsilon_{r}^{\prime}$ for the compound BBTZN and the fitting process, it is noted that the Lorenz formula is more accurate than the Gaussian formula for description the ferroelectric phase transition. It is deduced that the Curie-Weiss law which describes the temperature dependence of the dielectrics in the three phase transitions. The difference of eqn (8) and (9) is that the former supposes Gaussian distribution of PNRs at $T_{\mathrm{C}}$, and the latter supposes Lorentz-type distribution. From the above analysis, eqn (9) could describe the experience phenomenon precisely.

In addition, the diffuseness of the phase transition of relaxation can also be described by another empirical parameter such as $\Delta T_{\text {diffuse }}$ defined as: ${ }^{58}$

$$
\Delta T_{\text {diffuse }}=T_{0.9 \varepsilon_{r_{\max }}(1 \mathrm{kHz})}-T_{\varepsilon_{r_{\max }}(1 \mathrm{kHz})}
$$

where $T_{0.9 \varepsilon_{r_{\max }}(1 \mathrm{kHz})}$ corresponding to $90 \%$ of the temperature of the maximum of the real dielectric permittivity $\varepsilon_{r_{\max }}$ and $T_{\varepsilon_{r_{\max }(1 \mathrm{kHz})}}$ is their associated maximum at $1 \mathrm{kHz}$.

In order to quantify the frequency dispersion in the dielectric behavior, we define a parameter $\Delta \varepsilon_{r}^{\prime} / \varepsilon_{r}^{\prime}$ as:

$$
\frac{\Delta \varepsilon_{r}^{\prime}}{\varepsilon_{r}^{\prime}}=\frac{\varepsilon_{r_{\max }}^{\prime}\left(10^{2} \mathrm{~Hz}\right)-\varepsilon_{r_{\max }}^{\prime}\left(10^{5} \mathrm{~Hz}\right)}{\varepsilon_{r_{\max }}^{\prime}\left(10^{2} \mathrm{~Hz}\right)}
$$

The values of $\Delta T_{\text {diffuse }}$ and $\Delta \varepsilon_{r}^{\prime} / \varepsilon_{r}^{\prime}$ calculated and summarized in Table 2.

To further understand the relaxor nature of our compound, three models were used to describe the evolution of the maximum peak temperature of permittivity depending on frequency. The first model is that of Debye model based upon classical dielectric media. In Debye relaxation, dipoles are free to rotate and are thermally activated. The dipoles moments have the same values and there is no interaction between the dipoles; which can be written as follows: ${ }^{\mathbf{5 9}}$

$$
f=f_{0} e^{-\frac{T_{0}}{T_{\mathrm{m}}}}
$$

where $f$ is the attempt frequency, $T_{0}$ is the ratio of the activation energy to the Boltzmann constant $k_{\mathrm{B}}, T_{\mathrm{m}}$ is the temperature corresponding to this maximum.

To better understand relaxor ferroelectric character, the maximum dielectric constant $\left(T_{\mathrm{m}}\right)$ is found to obey VogelFulcher (V-F) model. ${ }^{60}$ This model takes into account the interactions between the dipoles. These interactions make the dipoles freeze at a particular temperature called freezing temperature. This model, described by the relation similar to that recognized for glasses, ${ }^{61}$ can be expressed as follows:

$$
f=f_{0} e^{-\frac{T_{0}}{\left(T_{\mathrm{m}}-T_{\mathrm{F}}\right)}}
$$

where $T_{0}$ is the ratio of the activation energy to the Boltzmann constant $k_{\mathrm{B}} \cdot f, f_{0}$ and $T_{\mathrm{F}}$, are respectively, the measurement frequency, the attempt frequency of dipole reorientation and the freezing temperature of the polarization below which the dynamic reorientation of the dipolar cluster polarization is not thermally activated.

The experimental values are fitted to eqn (12) and (13), and are shown in Fig. 7. The fitting results were computed for the sample and are given in Table 3 , for $T_{\mathrm{F}}=586 \mathrm{~K}$ and $E_{\mathrm{a}}=$ $0.052 \mathrm{eV}$ for region II and $T_{\mathrm{F}}=669 \mathrm{~K}$ and $E_{\mathrm{a}}=0.033 \mathrm{eV}$ for region III. Similarly, the low values of the activation energy are also found by Zhang et al. ${ }^{62}$ for $0.9 \mathrm{~Pb}\left(\mathrm{Mg}_{1 / 3} \mathrm{Nb}_{2 / 3}\right) \mathrm{O}_{3}-0.1 \mathrm{PbTiO}_{3}$ relaxors $\left(E_{\mathrm{a}} \approx 0.012 \mathrm{eV}\right), \mathrm{F}$. Bourgiba et al. ${ }^{63}$ for $\mathrm{BaTi}_{0.5}\left(\mathrm{Fe}_{0.33^{-}}\right.$ $\left.\mathrm{W}_{0.17}\right) \mathrm{O}_{3}$ ceramics $\left(E_{\mathrm{a}} \approx 0.0494-0.0586 \mathrm{eV}\right)$ and Tinberg ${ }^{64}(1-x)$ $\mathrm{BaTiO}_{3}-x \mathrm{BiScO}_{3}$ films $\left(E_{\mathrm{a}} \approx 0.05-0.12 \mathrm{eV}\right)$. The activation energy $E_{\text {a }}$, much lower in our ceramic, reflected a lower barrier between two potential wells. This range of features relating to the potential well reflected different polarization mechanisms. 

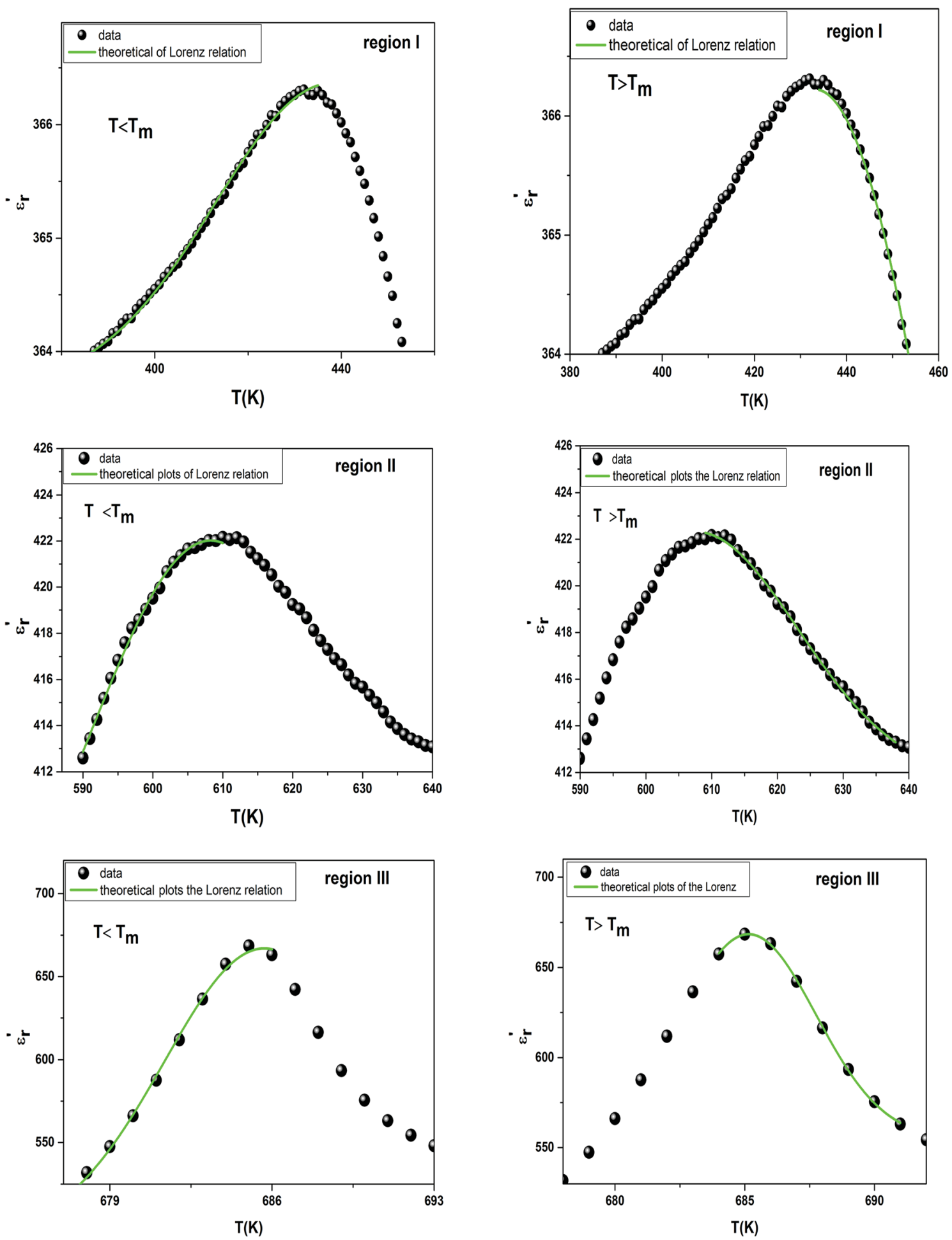

Fig. 6 The experimental and fitted dielectric data as a function of temperature for $\mathrm{Ba}_{0.97} \mathrm{Bi}_{0.02} \mathrm{Ti}_{0.9} \mathrm{Zr}_{0.05} \mathrm{Nb}_{0.04} \mathrm{O}_{3}$ ceramic using the Lorenz type.

The parameters $\left(E_{\mathrm{a}}, T_{\mathrm{F}}\right)$ indicate that the relaxation behavior is triggered by monopolars and similar to the thermally activated process of the spin glass in which the freezing process is controlled by cluster flipping and the intercluster interaction mechanism.

To overcome this limitation of $\mathrm{V}-\mathrm{F}$ model, Cheng et al. $^{65}$ proposed a power law:

$$
f=f_{0} e^{\left(-\frac{T_{0}}{T_{m}}\right) p}
$$

where $T_{0}$ is the ratio of the activation energy to the Boltzmann constant $k_{\mathrm{B}}$. The value of the parameter $p$ is a constant associated with the degree of relaxation of the material and can be used to describe the dielectric relaxation strength (DRS). A system exhibits a stronger dielectric relaxation for smaller value 

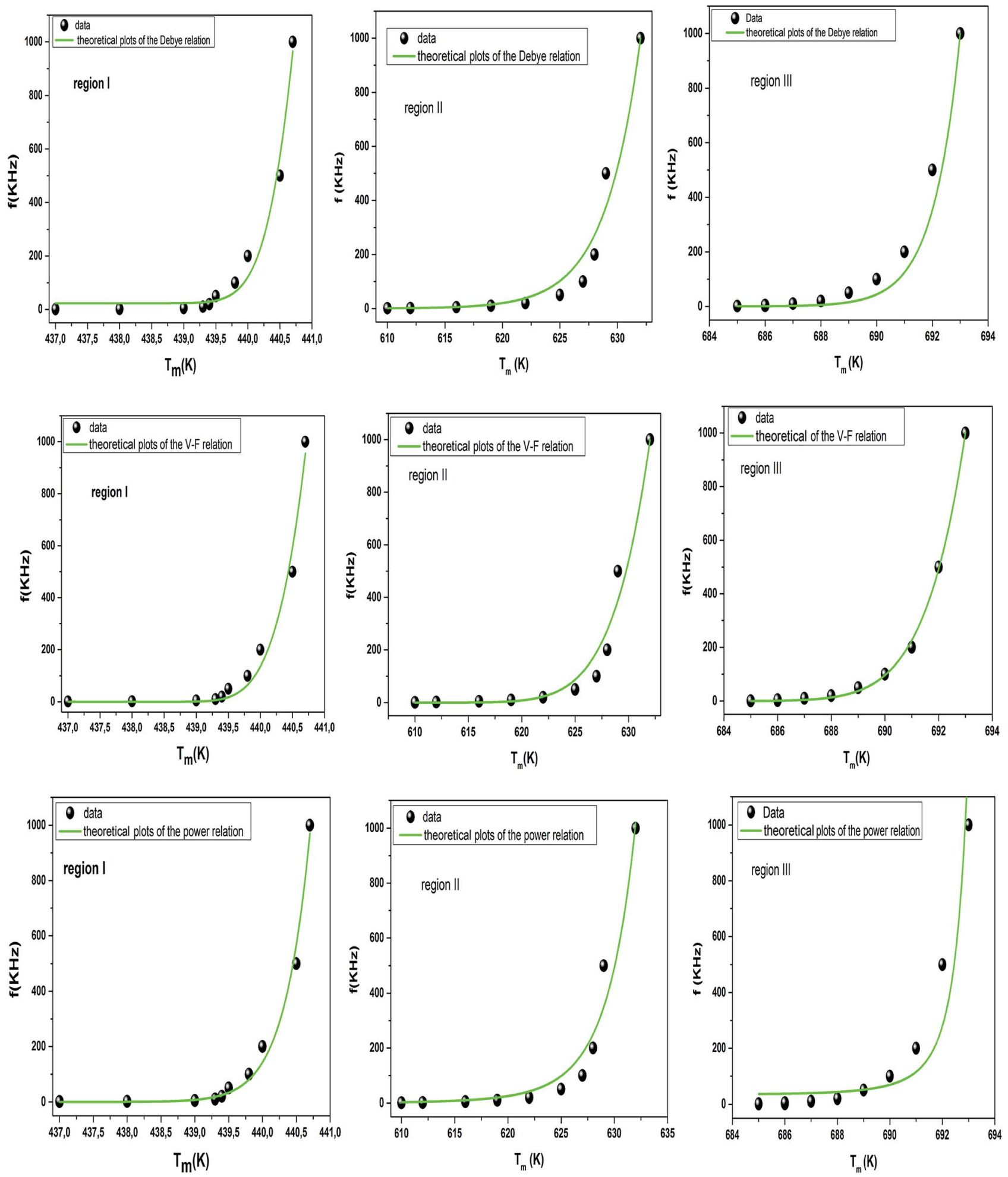

Fig. 7 Fitting of Debye, Vogel-Fulcher and Power models to the dielectric relaxation data of the $\mathrm{Ba}_{0.97} \mathrm{Bi}_{0.02} \mathrm{Ti}_{0.9} \mathrm{Zr}_{0.05} \mathrm{Nb}_{0.04} \mathrm{O}_{3}$ ceramic.

of $p$. If the value of $p=1$, the power model reduces to Debye model and will have strongest dielectric relaxation. For very low value of $p(=\infty)$, the system behaves like normal ferroelectrics and do not show any relaxation phenomena.

The fitted curves for Power model are shown in Fig. 7. The values obtained for their parameters are listed in Table 3. We notice that parameter $p$ (Table 4 ) is in agreement with those of the diffuseness coefficient $\gamma$ and $\Delta T_{\mathrm{m}}$, which confirms the relaxor behavior of the BBTZN sample.66 The pre-exponent factor $f_{0}$ provides an idea about the size of polar clusters and the degree of interaction between them. Smaller the size of the cluster, lower the interaction between them and hence the 
Table 4 Values of factors: Ea the thermal activation energy, the limit frequency of resonance of dipoles at high temperature $f_{0}$ and the freezing temperature $T_{F}$ of the dipoles for the $\mathrm{Ba}_{0.97} \mathrm{Bi}_{0.02} \mathrm{Ti}_{0.9} \mathrm{Zr}_{0.05} \mathrm{Nb}_{0.04} \mathrm{O}_{3}$ ceramic

\begin{tabular}{|c|c|c|c|c|c|c|}
\hline $\mathrm{Ba}_{0.97} \mathrm{Bi}_{0.02} \mathrm{Ti}_{0.9} \mathrm{Zr}_{0.05} \mathrm{Nb}_{0.04} \mathrm{O}_{3}$ & & $f_{0}(\mathrm{~Hz})$ & $E_{\mathrm{a}}(\mathrm{eV})$ & $T_{\mathrm{F}}(\mathrm{K})$ & $p$ & $\chi^{2}$ \\
\hline \multirow[t]{2}{*}{ Debye model } & Region I & $1.186 \times 10^{78}$ & 5.21 & - & - & 0.9745 \\
\hline & Region II & $4.175 \times 10^{66}$ & 2.8 & - & - & 0.95583 \\
\hline \multirow[t]{3}{*}{ Vogel Fulcher model } & Region I & $4.08 \times 10^{6}$ & 0.02 & 437 & - & 0.97969 \\
\hline & Region II & $6.1 \times 10^{8}$ & 0.052 & 586 & - & 0.99862 \\
\hline & Region III & $1.03 \times 10^{10}$ & 0.033 & 669 & - & 0.96206 \\
\hline & Region III & $2.6 \times 10^{5}$ & 0.021 & - & 7 & 0.97441 \\
\hline
\end{tabular}

larger value of $f_{0}$ and vice versa. The value of $p$ determines the degree of relaxation and hence the rate of growth of polar clusters. The higher the relaxation is, the slower the rate of growth of polar clusters is. The observed relaxation is related to the slower rate of growth polar clusters. In this compound the Polar clusters have undergone three relaxation areas which can increase their size and this may be a source of the relatively high grain size observed by SEM.

Comparing $\chi^{2}$ values, we notice the good agreement of the data with Vogel-Fulcher relationship, which suggests that the relaxor behavior in our compound is analogous to that of dipolar glass with a polarization fluctuation above a static freezing temperature.

The dielectric loss $(\tan \delta)$ of the compound BBTZN as a function of temperature up to $700 \mathrm{~K}$ at various frequency ranges from $1 \mathrm{kHz}$ to $1 \mathrm{MHz}$ is represented in Fig. 8(a). We observe a marked peak that shifts to higher frequencies with temperature, resembling the relaxor type dielectric behavior. The appearance of a broadened peak in the dielectric loss as a function of temperature is indicative of a transition from one type of relaxation process to another taking place at a characteristic temperature and may be attributed to the combined effect of the reorientation of thermally activated polar flips and loss of polarization with the rise in temperature. ${ }^{67}$ In addition, the high dielectric loss at higher temperature is supposed to be induced by the thermally activated space charge contribution (Maxwell-Wagner type). ${ }^{68}$

The electrical conductivity $\left(\sigma^{\prime}\right)$ of a dielectric material can be presented in terms of the dielectric loss $(\tan \delta)$ by the relation: ${ }^{69}$

$$
\sigma^{\prime}=\omega \varepsilon_{0} \tan \delta \varepsilon_{r}^{\prime}
$$

where $\omega=2 \pi f, f$ is frequency, $\varepsilon_{0}$ and $\varepsilon_{r}$ are the permittivity of free space and dielectric constant, respectively, and $\tan \delta$ is dielectric loss.

The temperature dependence of the electrical conductivity $\left(\sigma^{\prime}\right)$ for BBTZN is presented in Fig. 8(b). Results shown that $\sigma^{\prime}$ increases simultaneously with increasing the temperature and frequency. Moreover, the electrical conductivity curves show a typical feature of relaxation behavior. These results are in agreement with those obtained in the dielectric loss $(\tan \delta)$ (Fig. 8(a)).

The complex electric modulus was calculated from the dielectric permittivity $\left[\varepsilon^{*}(\omega)\right]$ using the following relation: ${ }^{70}$

$$
\begin{gathered}
M^{*}(\omega)=M^{\prime}+j M^{\prime \prime}=\left(\varepsilon^{*}\right)^{-1}=\frac{\varepsilon_{r}^{\prime}}{\varepsilon_{r}^{\prime 2}-\varepsilon_{r}^{\prime \prime 2}}+j \frac{\varepsilon^{\prime \prime}}{\varepsilon_{r}^{\prime 2}-\varepsilon_{r}^{\prime \prime 2}} \\
=\left(\varepsilon_{\infty}\right)^{-1}\left[1-\int_{0}^{\infty} \exp (-i \omega t)\left(-\frac{\mathrm{d} \phi(t)}{\mathrm{d} t}\right) \mathrm{d} t\right]
\end{gathered}
$$

With

$$
\phi(t)=\phi(0) \exp \left[-\left(\frac{t}{\tau}\right)^{\beta}\right]
$$
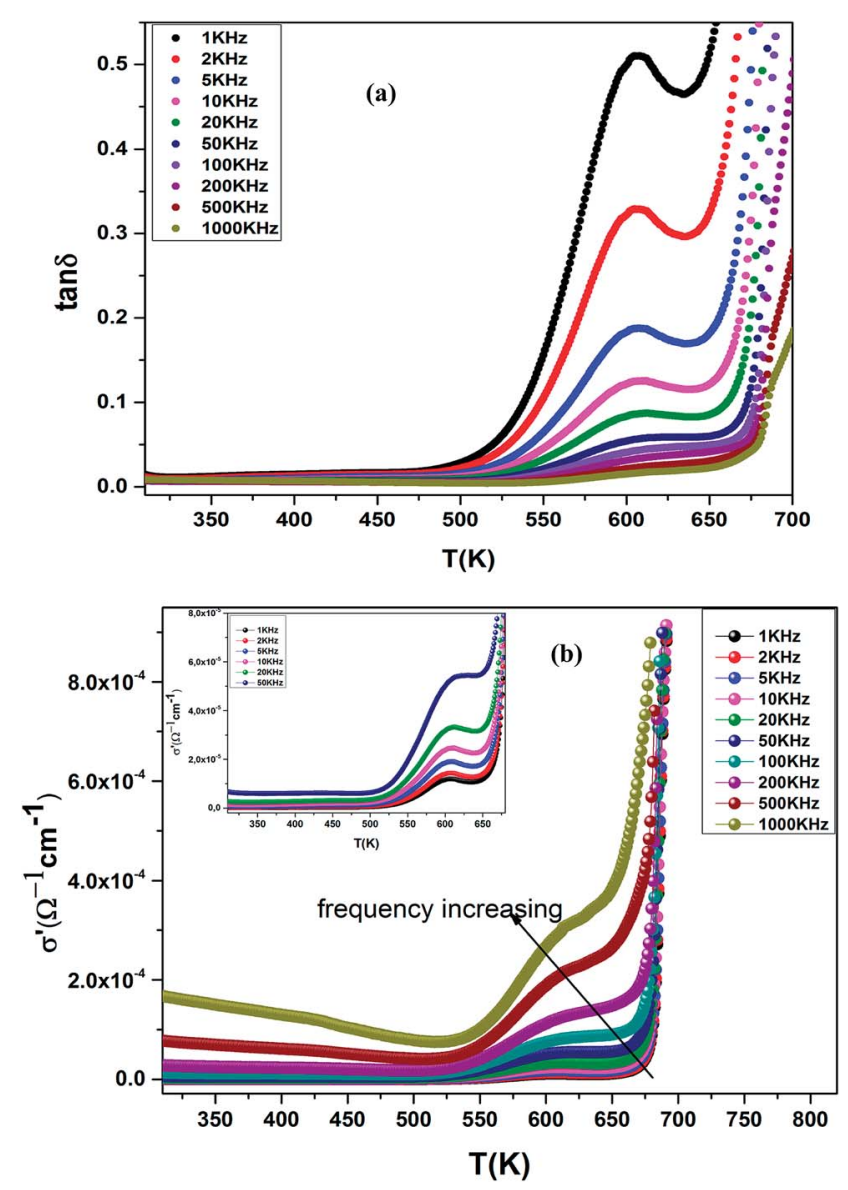

Fig. 8 (a) Temperature and frequency dependence of the dielectric loss (tan $\delta$ ) for $\mathrm{Ba}_{0.97} \mathrm{Bi}_{0.02} \mathrm{Ti}_{0.9} \mathrm{Zr}_{0.05} \mathrm{Nb}_{0.04} \mathrm{O}_{3}$, (b) the dielectric conductivity of this compound. 
where $\left(M^{\prime}, \varepsilon_{r}^{\prime}\right)$ and $\left(M^{\prime \prime}, \varepsilon_{r}^{\prime \prime}\right)$ are the real and imaginary components of modulus and permittivity, respectively, $j=\sqrt{-1}$ is the imaginary factor, $\varepsilon_{\infty}$ is the asymptotic value of real part of the dielectric constant, $\Phi(t)$ is the stretched exponential function of a material and $\beta(0<\beta<1)$ is the stretching coefficient and gives the degree of correlation between ions in ionic transport corresponding to complete uncorrelated ionic motion when its value is unity.

The temperature dependence of the electric modulus $M^{\prime}$ and $M^{\prime \prime}$ for various frequencies is shown in Fig. 9(a and b) for $\mathrm{Ba}_{0.97} \mathrm{Bi}_{0.02} \mathrm{Ti}_{0.9} \mathrm{Zr}_{0.05} \mathrm{Nb}_{0.04} \mathrm{O}_{3}$. We observed that, at lower temperature, $M^{\prime}$ tends to a constant value for all frequencies. This dependence indicates that the dielectric constant of the sample is thermally activated, similar to that of the dielectric constant spectrum by the presence of the phase transition with relaxor behavior (Fig. 3).

In addition, we see a two characteristic peaks in the temperature range. One is in the range of 300 to $600 \mathrm{~K}$ and the other lies between 600 and $800 \mathrm{~K}$. Correspondingly, $M^{\prime \prime}$ shows two peaks in the same temperature ranges. Both peaks shift to high temperature with increasing frequency indicating a thermally activated relaxation. This peaks were ascribed to the Maxwell-Wagner (M-W) space charge relaxation phenomenon, such as space charges, charged defects, and related defect
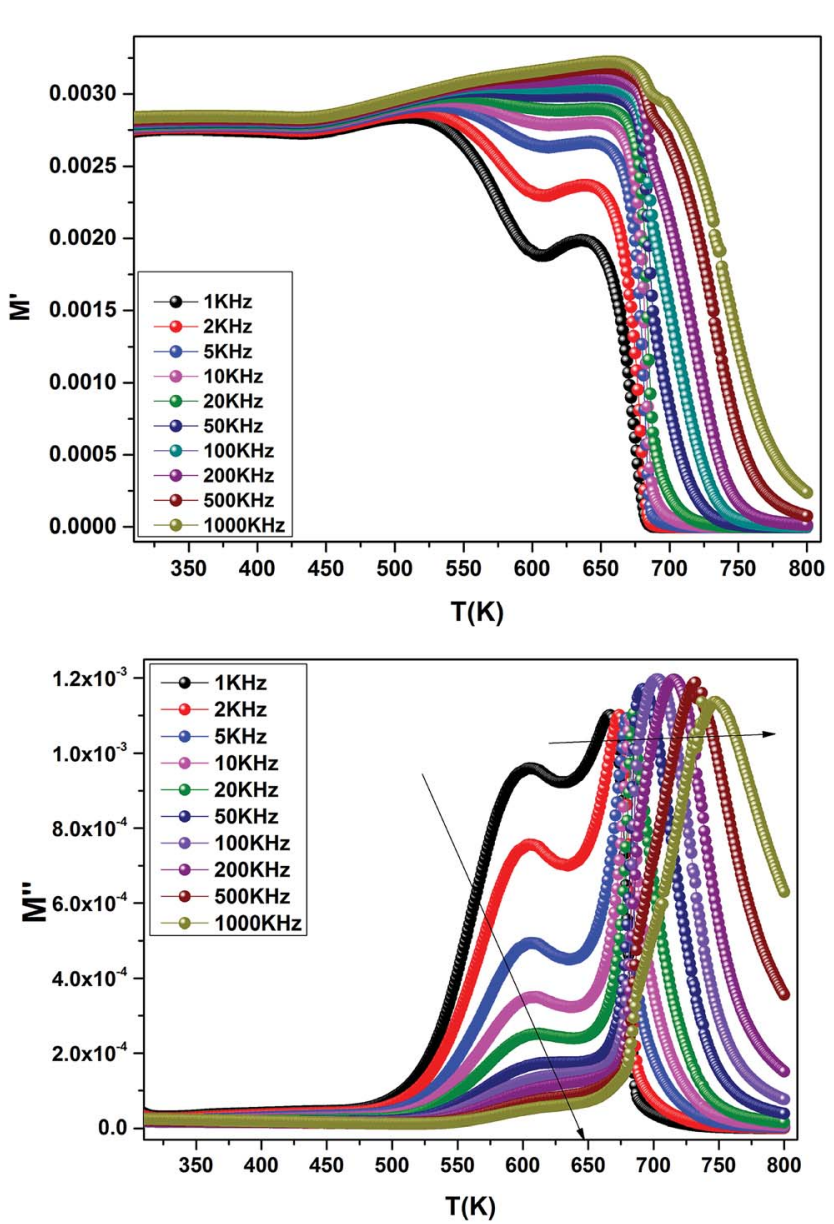

Fig. 9 Temperature dependence of the electric modulus ( $\mathrm{M}^{\prime}$ and $\left.\mathrm{M}^{\prime \prime}\right)$ for $\mathrm{Ba}_{0.97} \mathrm{Bi}_{0.02} \mathrm{Ti}_{0.9} \mathrm{Zr}_{0.05} \mathrm{Nb}_{0.04} \mathrm{O}_{3}$ at various frequencies. complexes. ${ }^{71}$ We attribute the low temperature peak to the dielectric relaxation and the high-temperature peak to the conduction process, similar to that of the conductivity spectrum (Fig. 8(b)). A thermally activated conduction process of defects produced during high temperature sintering such as oxygen vacancies and the presence of small grain boundary. Electrical inhomogeneities could be the possible reason for these high temperature dielectric relaxations. ${ }^{72}$

The results obtained in this study indicate that our ceramics are of extreme significance as far as their technological and industrial applications are concerned.

\section{Conclusion}

In summary, we have synthesized a new ceramic compound of composition $\mathrm{Ba}_{0.97} \mathrm{Bi}_{0.02} \mathrm{Ti}_{0.9} \mathrm{Zr}_{0.05} \mathrm{Nb}_{0.04} \mathrm{O}_{3}$ by molten-salt method. Rietveld analysis indicated that this sample crystallizes in pseudocubic structure with a $P m \overline{3} m$ space group. The temperature dependence of the dielectric properties was investigated in the frequency range $1 \mathrm{kHz}$ to $1 \mathrm{MHz}$. Importantly, $\mathrm{Bi}^{3+}$ substitution in A site and $\left(\mathrm{Zr}^{4+}, \mathrm{Nb}^{5+}\right)$ for $\mathrm{Ti}^{4+}$ in $\mathrm{B}$ site is found to induce chemical and structural inhomogeneity that leads lead to the formation of polar nanoregions, local structure distortions, and local charge imbalance reflected as increasing diffuseness in the transition. Indeed, three regions of dielectric relaxations were observed in the title perovskite at the temperature ranges of 350-500 K, 500-620 K and 620-720 K with a maximum in the dielectric permittivity that shifted to a higher temperature with increasing frequency. Moreover, to investigate the degree of the DPT, the modified Curie-Weiss law has been introduced to describe the relaxation behavior attributed to the contribution of PNRs. Using Vogel-Fulcher (VF) model, the estimated value of parameters $\left(E_{\mathrm{a}}, T_{\mathrm{F}}\right)$ indicate a low barrier between two potential yield to the presence of different polarization mechanisms in this compound. These observations suggest that the present system can be considered as a potential lead-free material for the nanotechnologies applications.

\section{Conflicts of interest}

There are no conflicts to declare.

\section{References}

1 T. Yamamoto and S. Takao, J. Appl. Phys., 1992, 31, 31203123.

2 R. K. Patel, P. Kumar, C. Prakash and D. K. Agrawal, Ceram. Int., 2012, 38, 1585-1589.

3 J. Li, H. Kakemoto, S. Wada, T. Tsurumi and H. Kawaji, J. Appl. Phys., 2006, 100, 024106.

4 H. Gong, X. Wang, S. Zhang, Z. Tian and L. Li, J. Appl. Phys., 2012, 112, 114119.

5 G. Smolenskii and A. Agranovskaya, Soviet Physics Solid State, 1960, 1, 1429.

6 G. Burns and F. H. Dacol, Phys. Rev. B, 1983, 28, 2527. 
7 H. Ursic, M. Santo Zarnik and M. Kosec, Smart Mater. Res., 2011, 2011, 1-6.

8 M. T. Lanagan, N. Yang, D. C. Dube and S. J. Jang, J. Am. Ceram. Soc., 1989, 72, 481-483.

9 R. Yimnirun, Ferroelectrics, 2006, 331, 9-18.

10 J. Kuwata, K. Uchino and S. Nomura, Ferroelectrics, 1981, 37, 579-582.

11 W. Chen, Y. Li, Q. Xu and J. Zhou, J. Electroceram., 2005, 15, 229-235.

12 G. Arlt, D. Hennings and G. de With, J. Appl. Phys., 1985, 58, 1619.

13 J. Xing, Z. Tan, J. Yuan, L. Jiang, Q. Chen, J. Wu, W. Zhang, D. Xiao and J. Zhu, RSC Adv., 2016, 6, 57210-57216.

14 A. J. Miller, A. Rotaru, D. C. Arnold and F. D. Morrison, Dalton Trans., 2015, 44, 10738-10745.

15 W. Bai, B. Shen, J. Zhai, F. Liu and Y. Zhang, Dalton Trans., 2016, 45, 14141-14153.

16 F. Bahri and H. Khemakhem, J. Alloys Compd., 2014, 593, 202-206.

17 T. Badapanda, S. K. Rout, S. Panigrahi and T. P. Sinha, Curr. Appl Phys., 2009, 9, 727.

18 S. Mahajan, O. P. Thakur, D. K. Bhattacharya and K. Sreenivas, J. Phys. D: Appl. Phys., 2009, 42, 065413.

19 H. Kaddoussi, N. Abdelmoula, Y. Gagou, D. Mezzane, H. Khemakhem and M. Elmarssi, Ceram. Int., 2014, 40, 10255-11026.

20 J. Li, H. Kakemoto, S. Wada and T. Tsurumi, J. Appl. Phys., 2006, 100, 024106.

21 C. Chen, H. Zhuang, X. Zhu, K. Zhou and D. Zhang, Ceram. Int., 2015, 41, 9893-9898.

22 Ch. Rayssi, S. El Kossi, J. Dhahri and K. Khirouni, J. Alloys Compd., 2018, 759, 93-99.

23 H. M. Rietveld, J. Appl. Crystallogr., 1969, 2, 65.

24 L. L. Zhang, Z. Xu, Z. Li, S. Xia and X. Yao, J. Electroceram., 2008, 21, 605-608.

25 A. Aoujgal, W. A. Gharbi, A. Outzourhit, H. Ahamdane, A. Ammar, A. Tachafine and J. C. Carru, Ceram. Int., 2011, 37, 2069-2074.

26 A. Taylor, X-Ray Metallography, Wiely, New York, 1961.

27 Z. Raddaoui, R. Lahouli, S. E. L. Kossi, J. Dhahri, K. Khirouni and K. Taibi, J. Alloys Compd., 2018, 765, 428-436.

28 A. Gholizadeh, Journal of Advanced Materials and Processing, 2015, 3, 71-83.

29 M. M. Vijatovic Petrović, R. Grigalaitis, N. Ilic, J. D. Bobi, A. Dzunuzovic, J. Banys and B. D. Stojanovi, J. Alloys Compd., 2017, 724, 959-968.

30 C. J. Li, F. Duewer, C. Gao, H. Chang and X.-D. Xiang, Appl. Phys. Lett., 2000, 76, 769.

31 T. Hayashi, N. Oji and H. Maiwa, J. Appl. Phys., 1994, 33, 5277.

32 T. Wang, J. Hu, H. Yang, L. Jin, X. Wei, C. Li, F. Yan and Y. Lin, J. Appl. Psychol., 2017, 121, 084103.

33 J. Wang, G. Rong, N. Li, C. Li, Q. Jiang and H. Cheng, Russ. J. Appl. Chem., 2015, 88, 533-537.

34 N. Haddadou, J. Belhadi, B. Manoun, K. Taïbi, B. Carcan, M. El Marssi and A. Lahmar, J. Mater. Sci.: Mater. Electron., 2018, 29, 16144-16154.
35 M. Kallel, I. Kriaa and H. Khemakhem, Ceram. Int., 2016, 42, 1379-1383.

36 B. E. Vugmeister and V. A. Stephanovich, Solid State Commun., 1987, 63, 323-327.

37 C. Mao, X. Dong, G. Wang, S. Cao and C. Yao, J. Am. Ceram. Soc., 2010, 93, 4011-4014.

38 K. Uchino, Ferroelectric Devices, Marcel Dekker, New York, 2000.

39 A. B. Hassen, F. I. H. Rhouma, J. Dhahri and N. Abdelmoula, J. Alloys Compd., 2016, 663, 436-443.

40 G. A. Smolensky, J. Phys. Soc. Jpn., 1970, 28, 26.

41 B. Y. R. D. Shannon, Acta Crystallogr., 1976, A32, 751.

42 F. Bahri and H. Khemakhem, Ceram. Int., 2013, 39, 75717575.

43 N. Haddadou, J. Belhadi, B. Manoun, K. Taïbi, B. Carcan, M. El Marssi and A. Lahmar, J. Mater. Sci.: Mater. Electron., 2018, 29, 16144-16154.

44 C. Lei, A. A. Bokov and Z. G. Ye, J. Appl. Phys., 2007, 101, 084105.

45 S. J. Kuang, X. G. Tang, L. Y. Li, Y. P. Jiang and Q. X. Liu, Scr. Mater., 2009, 61, 68-71.

46 B. Shen, Q. Zhang, J. Zhai and Z. Xu, Ceram. Int., 2013, 39, 913.

47 Y. Yanga, K. Liua, X. Liua, G. Liua, C. Xia, Z. Heb and Y. Yan, Ceram. Int., 2016, 42, 7877-7882.

48 K. Uchino and S. Nomura, Ferroelectr. Lett., 1982, 44, 55-61. 49 L. E. Cross, Ferroelectrics, 1994, 151, 305-320.

50 Z. Sun, L. Li, J. Li, H. Zheng and W. Luo, Ceram. Int., 2016, 42, 10833-10837.

51 S. Kumar and K. B. R. Verma, J. Phys. D: Appl. Phys., 2009, 42, 075405.

52 C. Filipic, Z. Kutnjak and R. Pirc, Phys. Rev. B, 2016, 93, 224105.

53 F. I. H. Rhouma, A. Dhahri, J. Dhahri, M. A. Valente and K. Khirouni, Appl. Phys. A, 2013, 114, 911-917.

54 S. Ke, H. Fan, H. Huang and H. L. W. Chan, Appl. Phys. Lett., 2008, 93, 112906.

55 G. Smolenskii and A. Agranovskaya, Soviet Physics Solid State., 1960, 1, 1429.

56 C. Mao, X. Dong, G. Wang, S. Cao and C. Yao, J. Am. Ceram. Soc., 2010, 93, 4011-4014.

57 S. Ke, H. Fan, H. Huang and H. L. W. Chan, Appl. Phys. Lett., 2008, 93, 112906.

58 W. Cai, C. Fu, J. Gao, Z. Lin and X. Deng, Ceram. Int., 2012, 38, 3367-3375.

59 Z. Y. Cheng, R. S. Katiyar, X. Yao and A. Guo, Phys. Rev. B, 1997, 55, 8165.

60 H. Vogel, Z. Phys., 1921, 22, 645-646.

61 G. S. Fulcher, J. Am. Ceram. Soc., 1925, 8, 339-355.

62 Q. Zhang, Z. Li, F. Li and Z. Xu, J. Am. Ceram. Soc., 2011, 94, 4335-4339.

63 F. Bourguiba, A. Dhahri, F. I. H. Rhoumaa, S. Mnefgui, J. Dhahri, K. Taibi and E. K. Hlil, J. Alloys Compd., 2016, 686, 675-683.

64 D. S. Tinberg, MS thesis, The Pennsylvania State University, 2006. 
65 Z. Y. Cheng, R. S. Katiyar, X. Yao and A. Guo, Phys. Rev. B: Condens. Matter Mater. Phys., 1997, 55, 8165.

66 D. Viehland, S. Jang, L. E. Cross and M. Wittig, J. Appl. Phys., 1990, 68, 2916-2921.

67 K. Li, X. L. Zhu, X. Q. Liu and X. M. Chen, Appl. Phys. Lett., 2012, 100, 012902.

68 Y. Zhang, H. Sunn and W. Chen, Ceram. Int., 2015, 41, 85208532 .
69 P. R. Mandal and T. K. Nath, J. Alloys Compd., 2015, 628, 379389.

70 S. Dutta, R. N. P. Choudhary, P. K. Sinha and A. K. Thakur, J. Appl. Phys., 2004, 96, 1607.

71 B. Li, Q. X. Liu, X. G. Tang, T. F. Zhang, Y. P. Jiang, W. H. Li and J. Luo, J. Mater. Sci.: Mater. Electron., 2017, 28, 1486414873.

72 G. Murugesan, R. Nithhya, S. Kalainathan and S. Hussain, RSC Adv., 2015, 5, 78414-78421. 